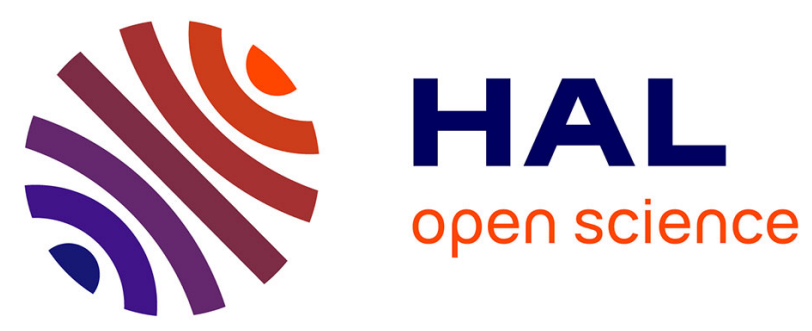

\title{
Discussion of "Revisiting the Energy-Momentum Method for Rating Vertical Sluice Gates under Submerged Flow Conditions" by Oscar Castro-Orgaz, Luciano Mateos, and Subhasish Dey
}

Gilles Belaud, Ludovic Cassan, Jean-Pierre Baume

\section{To cite this version:}

Gilles Belaud, Ludovic Cassan, Jean-Pierre Baume. Discussion of "Revisiting the Energy-Momentum Method for Rating Vertical Sluice Gates under Submerged Flow Conditions" by Oscar Castro-Orgaz, Luciano Mateos, and Subhasish Dey. Journal of Irrigation and Drainage Engineering, 2014, vol. 140 (nº 7), pp. 1-3. 10.1061/(asce)ir.1943-4774.0000691 . hal-01166275

\section{HAL Id: hal-01166275 \\ https://hal.science/hal-01166275}

Submitted on 22 Jun 2015

HAL is a multi-disciplinary open access archive for the deposit and dissemination of scientific research documents, whether they are published or not. The documents may come from teaching and research institutions in France or abroad, or from public or private research centers.
L'archive ouverte pluridisciplinaire HAL, est destinée au dépôt et à la diffusion de documents scientifiques de niveau recherche, publiés ou non, émanant des établissements d'enseignement et de recherche français ou étrangers, des laboratoires publics ou privés. 


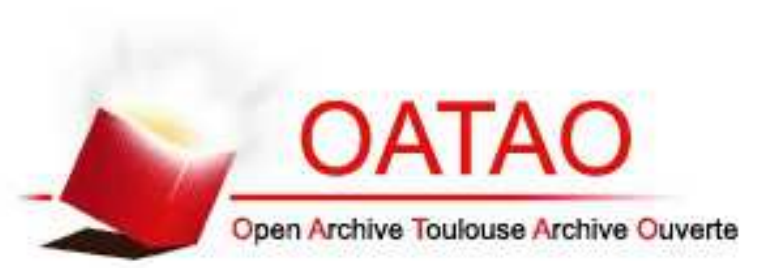

\section{Open Archive TOULOUSE Archive Ouverte (OATAO)}

OATAO is an open access repository that collects the work of Toulouse researchers and makes it freely available over the web where possible.

This is an author-deposited version published in : http://oatao.univ-toulouse.fr/ Eprints ID : 13862

To link to this article :

DOI: 10.1061/(ASCE)IR.1943-4774.0000691

URL: http://dx.doi.org/10.1061/(ASCE)IR.1943-4774.0000691

To cite this version : Belaud, G. and Cassan, L. and Baume, J. Discussion of "Revisiting the Energy-Momentum Method for Rating Vertical Sluice Gates under Submerged Flow Conditions" by Oscar Castro-Orgaz, Luciano Mateos, and Subhasish Dey. (2014) Journal of Irrigation and Drainage Engineering, vol. $140\left(\mathrm{n}^{\circ} 7\right)$. pp. 1-3. ISSN 0733-9437

Any correspondance concerning this service should be sent to the repository administrator: staff-oatao@ listes-diff.inp-toulouse.fr 


\section{Discussion of "Revisiting the Energy- Momentum Method for Rating Vertical Sluice Gates under Submerged Flow Conditions" by Oscar Castro-Orgaz, Luciano Mateos, and Subhasish Dey}

\section{G. Belaud ${ }^{1}$; L. Cassan ${ }^{2}$; and J.-P. Baume ${ }^{3}$}

${ }^{1}$ Professor, Unité Mixte de Recherche G-eau, Montpellier Supagro, 2 place P. Viala, 34060 Montpellier cedex 1, France (corresponding author). E-mail: belaud@supagro.inra.fr

${ }^{2}$ Assistant Professor, Institut de Mécanique des Fluides, Toulouse, allée prof. Camille Soula, 31400 Toulouse, France. E-mail: 1cassan@imft.fr

${ }^{3}$ Senior Hydraulic Engineer, Unité Mixte de Recherche G-eau, Irstea, BP 5095, 34196 Montpellier cedex 5, France. E-mail: jean-pierre .baume@irstea.fr

The discussers really appreciated the efforts to make more solid some usual assumptions used to derive reliable stage-discharge relationships, and the confrontation with field measurements. Energy and momentum equations are generally applied in their standard form, as presented in most hydraulic engineering books. The authors are right to point out that some of these assumptions are simplistic, which introduces biases in the derived relationships. Velocity distribution is one of these assumptions, and trying to improve this distribution is commendable. Head loss is another crucial issue, especially for submerged gates where the presence of the roller above the jet induced large dissipation. The authors also neglected the friction forces and assumed that contraction coefficient $\left(C_{c}\right)$ is the same in submerged flow as in free flow. This assumption was questioned by Henderson (1989), and Belaud et al. (2009) showed how to derive a continuous relationship for $C_{c}$ between low submergence $\left(C_{c}\right.$ about 0.61$)$ and fully open gate $\left(C_{c}=1\right)$. For submerged gates, there have been a limited number of experimental studies that explored the validity of the most sensitive assumptions. Compared to free flow, much more phenomena need to be quantified, such as head loss due to jet-roller interaction, velocity distributions at the contracted section and downstream measuring section, friction forces between these two sections. The effect of submergence introduces another dimension when trying to elaborate generic relationships. As the practical objectives are to obtain accurate discharge predictions, a common approach is to calibrate corrections using measured discharges, water levels, and openings. This may not be sufficient to validate physically based improvements since several phenomena compensate for each other.

The pioneer experimental works used by the authors provided very useful data sets to perform this analysis. This discussion is based on recent experimental and numerical results presented by Cassan and Belaud (2012). Experiments used acoustic Doppler velocimetry at selected locations, for three configurations in free flow and three in submerged flow. Computational fluid dynamics was used in complement, with the objective to interpolate flow characteristics between measuring points and to explore other configurations than those measured. Experiments were essential to verify the validity of the numerical results, based on ReynoldsAverage Navier-Stokes simulations with the volume-of-fluid method and Reynolds stress model as turbulence closure model. Notations are those of the discussed paper.

\section{Velocity Distribution}

One usual assumption is that the fluxes of energy and momentum in the roller are negligible. With an improved velocity profile, such
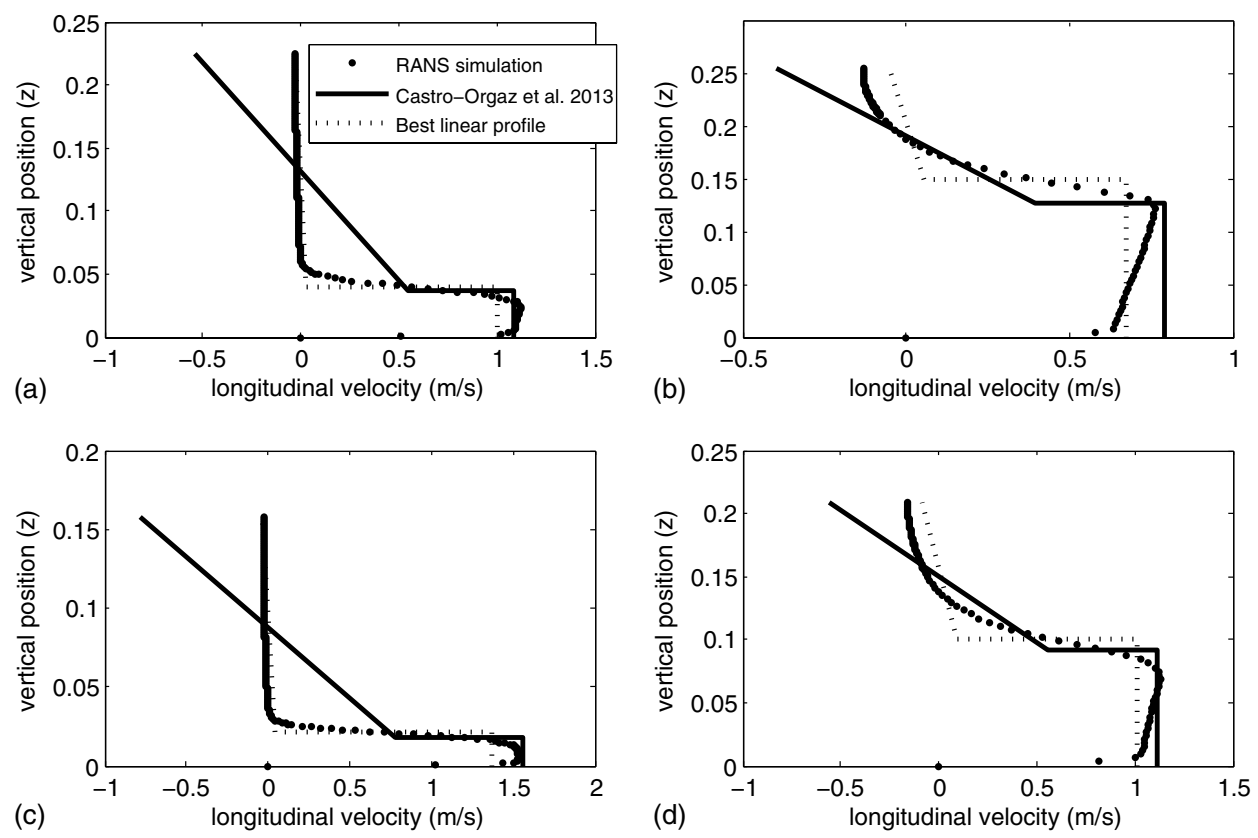

Fig. 1. Velocity profiles for various simulated configurations (selection of four typical configurations; other results are available on request); $V_{j}$ is obtained from calculated $C_{c}$ : (a) experiment $\mathrm{S} 05$; (b) experiment $\mathrm{S} 11$; (c) experiment $\mathrm{S} 13$; (d) experiment S20 


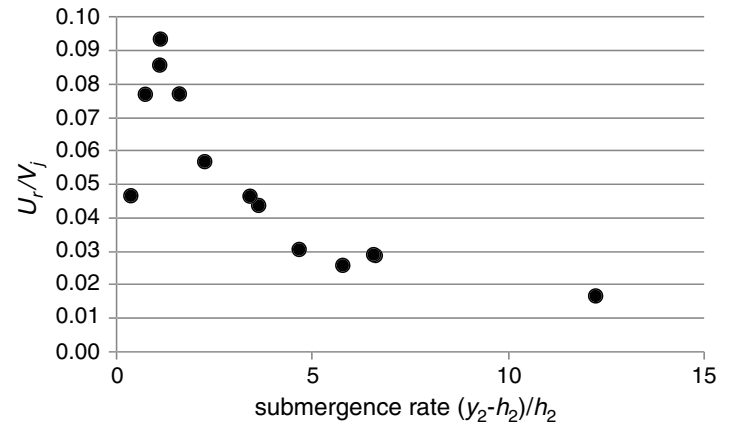

Fig. 2. Fitted values of $U_{r} / V_{j}$, as a function of submergence rate $\left(y_{2}-h_{2}\right) / h_{2}$

as the one proposed in the paper under discussion, these fluxes can be quantified. It further allows estimating a head loss coefficient [Eqs. (22) and (23)]. Considering a calibration on Boussinesq coefficients, the authors obtain $U_{r} / V_{j}=0.5$. This results in a correct fitting for some configurations, but not all. Fig. 1 presents the velocity profiles obtained at the contracted section (Section 2, see Fig. 1 of discussed paper), defined as the one where the jet thickness is minimum. For most flow conditions, it can be observed that $U_{r} / V_{j}$ should be closer to 0 than to 0.5 , which means that the configuration of Fig. 2(b) of the authors better describes the velocity distribution than the one of Fig. 2(c). The data set used in this discussion may be useful to find a relation between $U_{r}$ and $V_{j}$. RANS simulations indicate some dependency between $U_{r} / V_{j}$, obtained by a least square error fitting method on the velocity profiles, and relative submergence (Fig. 2). As expected, when the column of water above the jet is large, $U_{r}$ must tend to a very small proportion of the jet velocity, about $2 \%$ for experiment $\mathrm{S} 01$.

The fact that it better fits the relationship between $\beta$ and $y / h$ may be due to the experimental points considered by the authors in their analysis. They used indeed several points along the jet, whereas Fig. 1 above is only for Section 2. After mixing, the velocity profiles tend to uniformity, which explains why $U_{r} / V_{j}$ increases. As an example, Fig. 3 presents the velocity profiles along the jet for simulation S20. While $U_{r} / V_{j}$ is close to zero at Section 2, it regularly increases along the jet to reach the value of 1 far behind the roller. The value 0.5 is acceptable in average. Fig. 4 shows the values of $\beta$ calculated in the jet. Fig. 4(a) uses all the calculated locations within the jet, and corresponds to Fig. 3(a) of the authors. Values of $\beta$ are above the line $\beta=y / h$, and the highest values of $\beta /(y / h)$ are rather well described by Eq. (14) of the authors. However, the momentum equation (Eq. 3) should not use all these values but only the ones at Sections 2 and 3. In particular, the values of $\beta_{2}$ [Fig. 4(b)] do not present the same spreading as in Fig. 4(a) of this discussion or Fig. 3 of the authors. The best fitting gives $\beta_{2} \approx 1.064 y_{2} / h_{2}$. Using the velocity distribution of the authors, this in turn gives

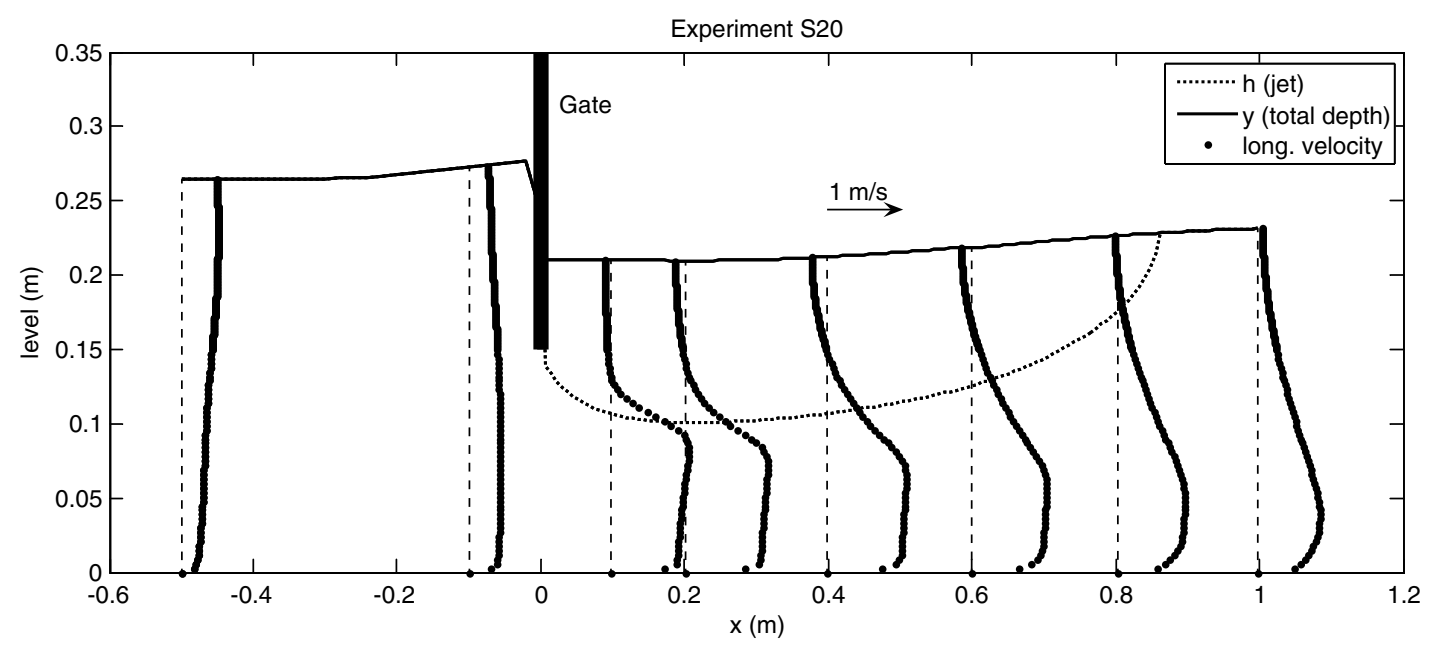

Fig. 3. Longitudinal velocity profiles at different locations, upstream and downstream of the gate
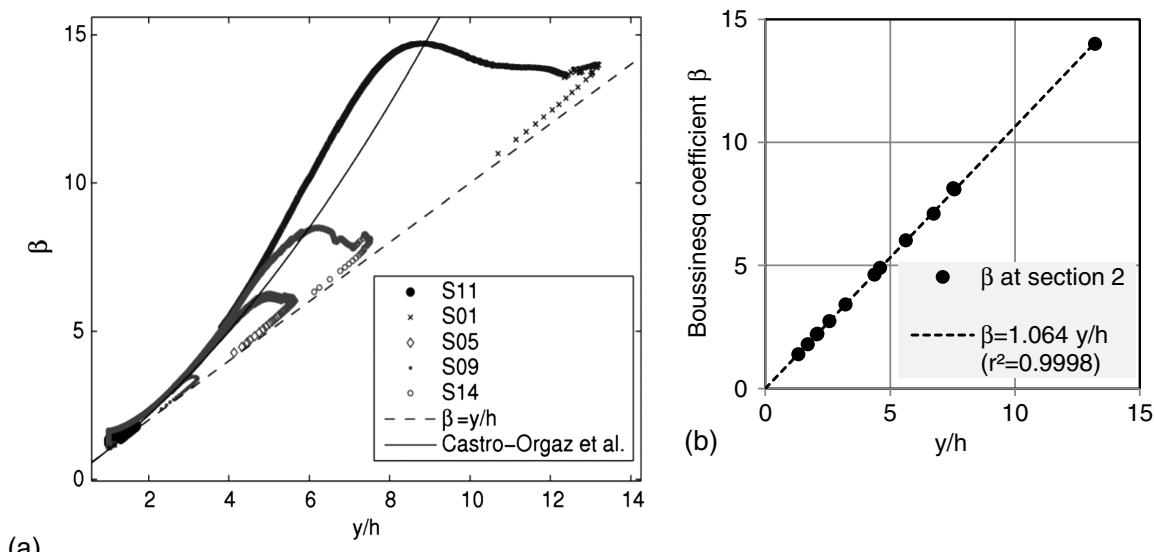

(a)

Fig. 4. Variation of $\beta$ as a function of $y / h$ : (a) all calculated locations, at different positions in the jet; (b) at the contracted section only (Section 2) 
Table 1. Calculated Variables for Selected Numerical Experiments in Submerged Flow

\begin{tabular}{|c|c|c|c|c|c|c|c|c|c|c|c|c|c|c|c|}
\hline $\begin{array}{l}\text { Experiment } \\
\text { name }\end{array}$ & $w$ & $Q$ & $y_{1}$ & $\alpha_{1}$ & $\beta_{1}$ & $C_{c}$ & $X_{2}$ & $y_{2}$ & $\alpha_{2}$ & $\beta_{2}$ & $\lambda$ & $y_{3}$ & $\alpha_{3}$ & $\beta_{3}$ & $U_{r} / V_{j}$ \\
\hline S 01 & 0.03 & 0.0145 & 0.298 & 1.090 & 1.031 & 0.671 & 1.05 & 0.266 & 189.1 & 14.0 & 0.054 & 0.269 & 16.6 & 5.1 & 0.017 \\
\hline S 04 & 0.06 & 0.0506 & 0.278 & 1.191 & 1.065 & 0.660 & 1.35 & 0.182 & 23.5 & 4.9 & 0.029 & 0.204 & 4.8 & 2.1 & 0.044 \\
\hline S 05 & 0.06 & 0.0413 & 0.288 & 1.174 & 1.060 & 0.663 & 1.35 & 0.224 & 35.3 & 6.0 & 0.028 & 0.234 & 8.4 & 3.0 & 0.031 \\
\hline S 06 & 0.06 & 0.0295 & 0.295 & 1.277 & 1.076 & 0.649 & 1.05 & 0.263 & 48.5 & 7.1 & 0.047 & 0.266 & 13.2 & 4.2 & 0.026 \\
\hline S 07 & 0.09 & 0.0438 & 0.290 & 1.049 & 1.019 & 0.660 & 1.45 & 0.260 & 20.7 & 4.6 & 0.019 & 0.264 & 9.0 & 3.1 & 0.047 \\
\hline S 08 & 0.12 & 0.0583 & 0.287 & 1.044 & 1.017 & 0.665 & 1.50 & 0.257 & 11.2 & 3.4 & 0.030 & 0.263 & 5.8 & 2.4 & 0.057 \\
\hline S 09 & 0.15 & 0.0731 & 0.284 & 1.062 & 1.023 & 0.664 & 1.55 & 0.256 & 7.1 & 2.7 & 0.016 & 0.263 & 3.8 & 1.9 & 0.077 \\
\hline S 10 & 0.18 & 0.0876 & 0.281 & 1.078 & 1.028 & 0.679 & 1.45 & 0.255 & 4.7 & 2.2 & 0.032 & 0.265 & 2.3 & 1.4 & 0.094 \\
\hline S 11 & 0.21 & 0.1018 & 0.276 & 1.107 & 1.039 & 0.714 & 1.20 & 0.255 & 3.1 & 1.8 & 0.060 & 0.268 & 1.5 & 1.2 & 0.077 \\
\hline S 12 & 0.24 & 0.1158 & 0.273 & 1.093 & 1.034 & 0.811 & 0.75 & 0.259 & 1.9 & 1.4 & 0.094 & 0.270 & 1.1 & 1.0 & 0.047 \\
\hline S 13 & 0.03 & 0.0290 & 0.281 & 1.034 & 1.012 & 0.695 & 1.55 & 0.158 & 63.8 & 8.1 & 0.017 & 0.179 & 1.8 & 1.2 & 0.029 \\
\hline S 14 & 0.03 & 0.0292 & 0.283 & 1.025 & 1.009 & 0.694 & 1.55 & 0.157 & 64.7 & 8.1 & 0.019 & 0.179 & 1.8 & 1.3 & 0.029 \\
\hline S 20 & 0.15 & 0.1029 & 0.265 & 1.187 & 1.065 & 0.673 & 1.40 & 0.209 & 4.6 & 2.2 & 0.036 & 0.232 & 2.2 & 1.4 & 0.086 \\
\hline
\end{tabular}

Note: $Q$ Discharge $\left(\mathrm{m}^{3} / \mathrm{s}\right) ; X_{2}=x_{2} / w$ relative position of vena contracta. Dimensional variables are in SI units.

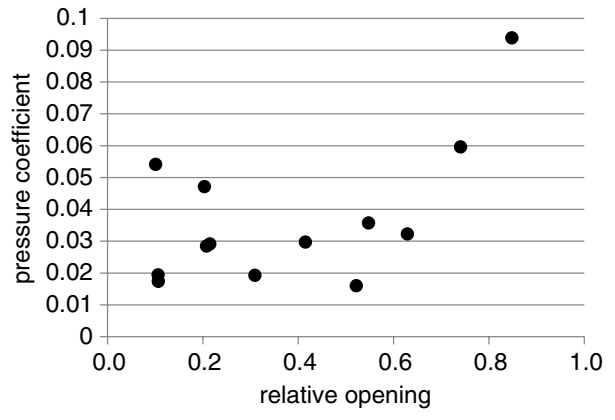

Fig. 5. Pressure correction coefficient

$$
\frac{U_{r}}{V_{j}}=\sqrt{3 \frac{0.064 h_{2}}{y_{2}-h_{2}}}
$$

with the asymptotic trend observed in Fig. 2, although it yields larger values than those obtained by fitting on velocity profiles. This suggests considering more complex velocity distributions.

\section{Revisiting Pressure Distribution, Contraction, and Friction}

Friction introduces head loss in the energy equation, as well as a friction force in the momentum equation. This force was not considered by the authors, as it is assumed to be counterbalanced by other effects. The discussers appreciate the link made between velocity distribution and head loss [Eqs. (22) and (23)]. There is no clear conclusion about the prediction of head loss coefficients, as the calibrated values depend on the underlying assumptions (regarding pressure and velocity distributions, friction force), but the approach is an encouragement to continue the efforts for improving physically based relationships. Among these assumptions, Rajaratnam and Subramanya (1967) showed that pressure is not perfectly hydrostatic at the vena contracta, and that the ratio $\lambda$ of bottom pressure head deviation to the kinetic energy was between 0.05 and 0.08 , which is consistent with the simulations used in this discussion (Table 1, Fig. 5). This effect is somewhat counterbalanced in the momentum-energy system of equations (Belaud et al. 2009), and the residual effect can be added to energy loss.

Contraction coefficient is another issue, particularly in submerged flow as it is not directly observed from the water profile. Experiments and simulation results show that the position of the vena contracta $\left(x_{2}\right)$ is between $w$ and $1.5 w$ downstream of the gate. The results also show that $C_{c}$ significantly deviates from 0.61 , particularly at large openings in submerged flows. However, as considered by the authors, $C_{c}$ can be considered as constant until $a \approx 0.6$, but then it largely increases to reach unity as the gate becomes fully open (Table 1). As pointed out by the authors, taking $C_{c}$ as a constant while calibrating the discharge equation on experimental data can be counterbalanced by other simplifying assumptions or by changing other coefficients, like velocity, pressure, or friction coefficients. This means that the energy-momentum (EM) method, although it may appear as physically based, remains an empirical method, so fitted relationships may not apply universally. Despite its complexity, it is still a promising method that can deal with particular gate configurations and flow regimes (like transitions from free to submerged flow or from gate to weir flow) frequently observed in irrigation systems. Further works should quantify the various effects, and lead to generic relationships that could be included in the EM method.

\section{References}

Belaud, G., Cassan, L., and Baume, J.-P. (2009). "Calculation of contraction coefficient under sluice gates and application to discharge measurement." J. Hydraul. Eng., 10.1061/(ASCE)HY.1943-7900.0000122, 1086-1091.

Cassan, L., and Belaud, G. (2012). "Experimental and numerical studies of the flow structure generated by a submerged sluice gate." J. Hydraul. Eng., 10.1061/(ASCE)HY.1943-7900.0000514, 367-373.

Henderson, F. M. (1989). Open channel flow, MacMillan Publishing, New York.

Rajaratnam, N., and Subramanya, K. (1967). "Flow immediately below submerged sluice gate." J. Hydr. Div. ASCE, 93(4), 57-77. 